\title{
Policing Political Ads: AN ANALYSIS of Five LEADING NEWSPAPERS' RESPONSES to 1992 Political AdVertisements
}

By Lori Melton McKinnon, Lynda Lee Kaid, Janet Murphy, and Cynthia K. Acree

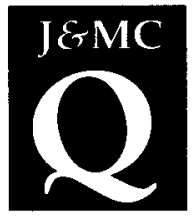

Researchers analyzed the content of five leading newspapers' coverage of 1992 political advertisements. Findings revealed that newspaper ad watches focused more on negative than on positive television spots, particularly those offered by incumbents rather than challengers. Political ads tended to be issue rather than image oriented. The researchers suggest that gatekeepers frame ad watches as priority agenda items. Although the visual and verbal content of the political spots are often discussed, most ad watch features fail to analyze ethically suspect techniques.

Conventional campaign wisdom holds that political news coverage may define the content of political advertisements. Recently, however, political advertisements have been shaping the content of the news. West writes, "Just as it is possible to shape people's impressions of how well candidates are doing, television ads can influence and reflect views of the campaign agenda." 1 Thus, contemporary candidates can use their own commercials to define the campaign dialogue.

Obviously, there has been a shift from the early belief that the media had little effect on audience members. Patterson and McClure once doubted that voters could learn from political news coverage. In fact, they concluded that voters learn more from political advertisements than from campaign news. However, Patterson modified his earlier findings to say that journalists' decisions about what coverage to stress does affect voters. ${ }^{2}$

As political advertisements have gained recognition as an important source of campaign information, reporters have begun taking an active "watchdog" role in analyzing campaign ads. Such analysis, journalists say, is part of an obligation to provide a picture of political reality other than the one that candidates place before the public. ${ }^{3}$ Political consultant Roger Ailes explains, "... journalists, who had begun to feel ignored, decided to go on the offensive. They vowed to protect the American people and formed, as Michael Oreskes of the New York Times termed it, "a self-appointed journalistic 'police force' to clean-up campaign advertising., ${ }^{\prime 4}$

JEMC Quarterly Vol. 73, No. 1 Spring 1996 66-76 C1996 AEJMC
Lori Melton McKinnon is an assistant professor of advertising and public relations in the College of Communication at the University of Alabama. Lynda Lee Kaid is a professor in the Department of Communication and the director of the Political Communication Center at the University of Oklahoma; Cynthia K. Acree is an account executive for the integrated marketing communications firm The Evans Group in Dallas, Texas; and Janet Murphy is an assistant professor in the Department of Communication at Oklahoma Christian University. 
Such news accounts can provide a framework to help voters understand ads. However, only if reporters question the legitimacy of the advertising claims can a "watchdog" approach actually aid the political process. Unfortunately, journalists often fail to look past the factual information in the ads to examine their meaning. According to Jamieson, during 1988,17\% of newspaper coverage focused on advertising content while only $1.7 \%$ dealt with the accuracy of advertising claims. Thus, by failing to reframe political advertisements, the power of the messages may be enhanced. ${ }^{5}$

In fact, credible news coverage of political advertisements, even if negative, does not necessarily hurt the commercial sponsor. Actually, it may benefit the campaign in two major ways. First, the advertisement receives unpaid access to millions of voters. In a content analysis of television news coverage of political advertisements airing between 1972 and 1988, Kaid et al. found that a substantial number of ads are aired during television news coverage of political advertising and that the majority of ad watches (69.5\%) aired in the first ten minutes of the newscast. Not only do ads receive unpaid access to voters, but they gain such access at the beginning of the newscasts, when the most important news agenda items are presented.

Secondly, news coverage legitimizes false or misleading claims in advertising by airing messages in a news environment. People trust the news to be fair and objective and believe it more credible than political advertisements. Kaid et al. argued that news coverage thus legitimizes ads and suggested four reasons for news emphasis on advertising content: (1) political ads feed on modern media needs, providing an effortless source of political news; (2) ads act as a form of political discourse, making it technically possible for candidates to communicate by responding to one another through ads; (3) the dramatic, controversial, and often emotional nature of political ads fits the "horse race" coverage emphasized by journalists; and (4) the ads themselves become a campaign issue. ${ }^{6}$ In addition, an experiment by Pfau and Louden revealed that some ad watches produce a boomerang effect, further enhancing the influence of the targeted ad itself." Ailes explains, "You get a $30 \%$ to $40 \%$ bump out of an ad by getting it on the news. You get more viewers, you get more credibility, you get it in a framework." 8

Such findings have led political consultants to develop campaign strategies to assure that their candidate's message is aired. For example, a 1980 radio spot opened with the word "Bullshit!" to gain media attention. Producer Bill Zimmerman admits to using this strategy in order to secure news coverage and to acquire free media time previously denied to his candidate's campaign. ${ }^{9}$ Other consultants have responded to ad watches by providing "citations" or "footnotes" for the information they are presenting. Commercials often include visuals of the actual newspaper clippings or government reports. ${ }^{10}$ In addition, media reviews are often incorporated into the political advertisements themselves. As political news covers advertisements, and as advertisements incorporate news coverage, the line between advertising and news content becomes blurred for voters.

Most critiqued advertisements consist of "adbites" which are equivalent to soundbites and fit easily into allotted media time or space. Adbites shape the language and visual imagery of the news. If the news accounts are inconsistent with the advertisement, the power of the advertisement may be diminished. However, when the two are consistent, the power may be magnified. According to Jamieson, visually evocative, controversial, and humorous opposition (attack) ads gain the majority of media attention. In fact, during 1989 and 1990, newspapers were six times more likely to cover 
negative advertisements than to cover positive ones. ${ }^{11}$ This finding is in line with results of a content analysis that found negative ads receive more analysis than do positive ones during network television news programs. ${ }^{12}$ By emphasizing negative advertising in campaign coverage, voters may receive a skewed view of an overly negative campaign.

How voters give meaning to news messages is critical to the campaign process. Jamieson found that people more easily recall advertisements than the news coverage that surrounds them. Exposure to part of the advertisement actually may evoke the entire ad in the minds of voters. Therefore, exposure to a single media critique cannot compete with an advertisement that has been repeated time and time again. Jamieson also demonstrated that members of focus groups more easily recall political ads than corrections offered by media analysis.

According to Jamieson, such findings led to changes in the presentation of advertisement reviews. For example, many newspapers placed advertisement reviews in "truth boxes" or labeled reviews as "ad watches." 13 A typical format for boxes might include a picture of the video image, the commercial script, the cost of the media buy, names of the producers, reaction to the ads assertions, and a point-by-point analysis of major elements. ${ }^{14}$ Likewise, television stations took similar approaches in order to separate the ad review from the ad itself.

In many cases, advertisements were downsized and placed in a box or television set graphic on the screen. According to West, Kern, and Alger, "This downsizing of video in the Ad Watch is an important advance because it undercuts the visual impact of the advertisements."15 Additionally, some stations used graphic overlays to indicate that the image being shown was only a review of an ad. CNN reporters often placed text across the commercial such as "falsehood," "misleading," or "unfair," and NBC political analysts attached "false" labels or put a "red X" over the ad. Other newscasters warned viewers that they were about to review an advertisement by declaring a "time out." Such practices attempted to reduce the political advertisements' credibility. ${ }^{16}$

In America, a voter's political reality is shaped by mass mediated experiences and, possibly, by mediated analyses. Results from a field experiment by Cappella and Jamieson indicate that ad watches have the ability to affect voters' attitudes toward the source of the ad, perceived fairness of the ad, and perceived importance of the ad. ${ }^{17}$ Thus, as political advertisements increasingly capture media and public attention, it is vital for scholars to investigate the ways in which newspaper "ad watches" cover campaign commercials.

The researchers approached the study with the expectation that newspaper ad watches would analyze negative ads more than positive ads, the majority of ad watches would be placed in the first section of the newspapers, and the majority of ad watches would appear in the form of truth boxes rather than in the form of articles. Because newspapers pride themselves on providing objective coverage and on giving attention to campaign issues, the researchers also expected that newspaper ad watches would cover issue ads more than image ads and that the dominant tone of ad watches would be neutral. Finally, the researchers were interested in pursuing several other research questions that focused on how the ads were covered, whether the ethical nature of the ads was discussed, and whether other characteristics of the ads (party or gender of candidate, level of race, visual aspects) were analyzed. 
Researchers conducted a content analysis of five leading newspapers' coverage of 1992 political advertisements. The fivenewspapers chosen are all major dailies with high circulations that give considerable attention to the coverage of politics. Newspapers were selected to achieve regional distribution. The resulting sample consisted of five papers: Los Angeles Times, New York Times, The Miami Herald, Chicago Tribune, and Washington Post. All of these newspapers covered the Presidential election, and most covered local or regional Senate and House of Representative races.

Researchers examined all political advertising stories appearing in these newspapers from Labor Day (6 September) to Election Day (2 November) 1992, dates traditionally viewed as the general election period for political campaigns. According to Kern, West, and Alger, ad watches amplify the most memorable messages and place greater emphasis on campaign issues during this period. ${ }^{18}$

The unit of analysis for this project was the advertisement feature (news article or truth box). All features on advertisements for federal races (Congress, Senate, or President) were analyzed. The total number of stories $(n=126)$ included 26 articles from the Los Angeles Times; 50 articles from the New York Times; 21 articles from the Miami Herald; 8 articles from the Chicago Tribune; and 21 articles from the Washington Post. For all advertising stories appearing in this period, coders recorded the date and day of week published, the newspaper, the length of story, and the feature type (article/truth box).

In addition, researchers devised categories to address the information given in the ad feature specifically concerning the political advertisement being evaluated. Coders determined the following information: if a photograph from the advertisement appeared; the number of ads shown; candidate's name; commercial name; date the advertisement aired; media consultant's name; length of spot; candidate gender; candidate status (incumbent, or challenger); political party (Republican, Democrat, Independent, combination, or other); office sought (Senate, House, President, or combination). They also examined whether the audio and the video content of the ad was analyzed by the news feature. Additionally, they looked for approaches identified (humor, emotion, drama, controversy, and shock) and for ethically suspect categories. For this latter category, the researchers used the definitions and descriptions of potential abuses outlined by Kaid including editing, special effects, visual imagery, dramatization, subliminal messages, and computerized alteration. ${ }^{19}$ Coders also recorded the dominant content (image, issue, or a combination) of the advertisement, and the dominant focus of the advertisement (positive, negative, or combination). In the latter case, "positive" advertisements were those promoting the candidate; "negative" advertisements were those attacking the opponent or his/her positions; and "combination" advertisements were those where an equal number of positive and negative advertisements were covered.

Researchers coded content in the following categories: main focus of ad feature (if the advertisement was the dominant focus of the feature or if it was just part of broader story); type of article (routine campaign report, special feature on advertising, candidate profile, or issue feature); placement of story (first, second, third, or fourth section of the newspaper); type of experts cited if any (independent political consultant, campaign's media or political consultant, campaign or party official, candidate or running mate, 
journalist, or academic resource). Moreover, coders determined the dominant approach of the article. The coders were instructed to code the tone of the article as "positive" if the article favored the candidates' ad, as "negative" if the report implicitly or explicitly criticized the candidate or the campaign for advertising strategies, as "neutral" when the article was balanced between positive and negative critiques, and as "unable to determine" if the coder couldn't tell from the information given.

Two trained undergraduate students coded the political advertising features. Intercoder reliability averaged $+.91 .^{20}$

\section{Results}

Analysis of the 126 newspaper ad watch articles substantiated many of the research expectations. As Table 1 indicates, newspaper ad watches focus more heavily on negative ads than positive ones. In fact, $62 \%$ of the ad watches analyzed a negative political spot. This does, however, represent a lower percentage than Kaid reported for $1988(77 \%)$ of television news ad analyses. ${ }^{21}$ Among the factors that may account for the difference are change over time and type of media.

Newspapers pride themselves on giving in-depth attention to campaign issues which led to the expectation that the ad watches would focus on issue-oriented ads. This expectation was borne out by the data in this study. Newspapers placed most $(83 \%)$ of the ad watch stories in the first section of the newspaper. Similarly, previous studies report that television ad watch stories tend to appear during the first ten minutes of a network newscast. ${ }^{22}$

TABLE 1

Approaches Taken in Ad Watch Coverage

$(\mathrm{n}=126)$

Focus of Ad Covered

Positive

Negative

Can't Determine

Type of Ad Covered

Issue $\mathrm{Ad}$

Image Ad

Combination

Can't Determine

Placement of Ad

First Section

Other Section

\section{Form of Ad Watch Stories}

Truthbox

Article

Combination

Approach Taken in Ad Watch

$\begin{array}{lrr}\text { Positive } & 4 & (3 \%) \\ \text { Negative } & 13 & (10 \%) \\ \text { Neutral } & 109 & (87 \%)\end{array}$


However, only $47 \%$ of newspaper ad watches have adopted the television trend of enclosing advertising analyses in "truth boxes." The content in the analyses tend to be neutral. (See Table 1.)

Several other aspects of newspaper ad watch coverage were addressed by this content analysis. Because earlier research indicated that Republicans are more heavily scrutinized than are Democrats, partisan characteristics of the ad watches were studied. ${ }^{23}$ Although analyses of 1992 presidential political advertisements indicate that the Democratic presiden-

\section{TABLE 2}

Specific Characteristics of Newspaper Ad Watch Stories

$$
(\mathrm{n}=126)
$$

Party of Candidate's Ad Analyzed

Republican
Democrat

Office Sought by Candidate of Analyzed Ad

President

Senate

House

Combination

Other

Candidate Status

Incumbent

Challenger

Combination

Other

Gender of Candidate

Male

Female

Both

Other (Groups)

Amount Advertising Copy Printed

Entire Copy $\quad 68$

Partial Copy

Video Content of Ad Analyzed

Picture of Ad Shown

Video Techniques Identified as Suspect

Editing
Special Effects
Visual Imagery
Dramatizations
Computer Alterations


tial candidate aired a substantially higher percentage of negative ads than did the Republican candidate, ${ }^{24}$ in this study Republicans were more likely to have their negative ads analyzed than were Democrats. Nearly $84 \%$ of Republican ads analyzed were negative ads, compared to $58 \%$ for Democrats [chi square $=27.16(9), p=.04$ ]

The presidential race dominated ad watches in newspapers (See Table 2). Analyses of presidential spots comprised the content of $70 \%$ of the newspaper ad watches. Twenty-two percent were directed toward U.S. Senate candidates, and only 3\% toward House candidates. Ad watches also focused on ads for general parties, such as the Democratic National Committee thirty-second commercials that called for elderly Americans to remember that, "Every year for the past twelve years, the Republicans tried to cut Medicare," and asked them to vote for Democratic candidates. Some targeted political issues. Included in this category were watch notes on the National Abortion Rights Action League's thirty-second commercial aimed at defeating Senator D'Amato and other prolife candidates.

Challengers received much more scrutiny than did incumbents. (See Table 2). However, incumbents were more likely to have their negative ads scrutinized than were challengers, since $84 \%$ of the incumbent ads analyzed were negative, compared to $58 \%$ of challenger ads [chi square $=27.96(9), p=$ .001].

Female candidates, who incidentally were included as major U.S. Senate and House candidates in several states, received only seven ad watch stories in the entire sample of 126 features. Although the Washington Post did not run any ad watches specifically focusing on a female candidate's ad, they did run five ad watches on lower-level races. The papers that ran ad watches focusing specifically on female candidate advertising strategies included: Chicago Tribune (1), Miami Herald (2), New York Times (2), and Los Angeles Times (2). Most of these same papers gave greater attention to male Senate and House candidates' ads: Chicago Tribune (3), Miami Herald (2), New York Times (14), and Los Angeles Times (4).

When one focuses only on Senate and House races covered $(n=33$ features), 7 ad watch features $(21 \%)$ focused on female candidate ads, while 26 features $(79 \%)$ focused on male candidates' advertising strategies. Of the male candidates' ads discussed, 12 (46\%) centered on ads which attacked their female opponents. Although differences are not statistically significant, it may be beneficial for future studies to investigate whether or not female candidates utilize advertising strategies which merit ad watch coverage.

Another aspect of the ad watch coverage that interested the researchers was the extent to which the newspaper coverage of the television ads addressed the visual aspects, as well as the verbal content of the ads. Many researchers have argued that the visual aspects of television ads are an important part of their content and make up an important aspect of their "videostyle." 25 The results here indicated that newspaper ad watches are attempting to address visual and verbal aspects of the ads. (See Table 2)

A final aspect of ad watch coverage related to whether the newspaper story analyzed the ethical use of technology. Kaid has identified several aspects of audio and video techniques used in political spots that can result in ethically-suspect spots. ${ }^{26}$ Table 2 shows that, while newspapers have not completely ignored these issues, they have not devoted substantial attention to them. Some stories identified editing techniques used in the spot as potential problems. Others discussed the troublesome use of dramatization, special effects, computerized alteration, and visual imagery. 
One of the most meaningful findings from this analysis is that an overwhelming majority of ad watches appeared in the first section of the paper. This relates to Kaid et al.'s conclusion that the majority of televised ad watches appeared in the first ten minutes of newscasts. ${ }^{27}$ Although some might argue that this is a logical placement for political news, the fact remains that ad watches receive high priority. The implications of this are farreaching in relation to the agenda-setting function of the press and merit further study.

Another important finding is that advertisement features appeared slightly more often in the form of articles than in the form of truth boxes. This finding was surprising as previous literature indicates a trend toward greater use of truth boxes as a way of separating accuracy from effectiveness and of labeling advertisement reviews. ${ }^{28}$

Surprisingly, few ad features analyzed ethically suspect categories. Kaid defines ethically suspect techniques as any audio or video technique that creates a false, distorted, or deceptive impression. Consequently, Kaid suggests guidelines that researchers can use in order to address questions concerning ethically suspect political advertising. ${ }^{29}$ Technological advancements have made it possible to mislead voters through the use of editing techniques, special effects, dramatization, subliminal messages, visual imagery, and computerized alteration.

Of the 126 ad watches analyzed, only three of the above categories were identified at low levels - from $36 \%$ to $14 \%$. Editing techniques (the ad content was edited to alter the sequence of events, rate of speech, etc.) were discussed most often. For example, a Clinton ad juxtaposed images of Bush speaking on the job rate with narration indicating that the opposite held true (Bush: "80 million jobs in the next eight years," Narrator: "1990, America's jobless rate hits a three-year high," Bush: "I'm not prepared to say we are in a recession," etc.). This ad is suspect because the events Bush was speaking at were not directly related to the times referred to in the ad. The second most commonly discussed technique was dramatization (an event was dramatized to appear real). A Bush ad showed a group of people discussing his success in the previous night's debate at an International House of Pancakes. The video cameras were even jerked to make the discussion seem less like a professional advertisement. More outrageous dramatizations included an ad that used mock media to claim that "Elvis endorses Feingold for Senate" and an ad that resembled a pop-music record commercial for "Leslie's [Bryne] Big Tax Hits" with songs such as "Hey, Big Spender," etc. Finally, reporters discussed special effects. An example of the use of special effects is an ad by the National Abortion Rights Action League aimed at defeating New York Senator D'Amato. This ad shows silent images of D'Amato speaking, the camera then focuses on his face, and as the sound of a ticking clock grows faster, the focus tightens until D'Amato's eye fills the screen in a blob that fades into the final words.

Although reporters rarely discussed (6\% or less) other ethically suspect categories, a few good examples were provided. Indeed, one ad by Florida Senator Margolis featured strong visual imagery (images were used to evoke strong responses) to suggest that her opponent U.S. Rep. Clay took extremist positions on issues. Words such as "wrong on choice" and "wrong on gun control" were played over pictures of coat hangers and a revolver. In addition, reporters discussed several instances where computerized alteration techniques (computers were used to alter images or reality) were 
utilized. For example, a Bush ad showed a split-screen visual of two candidates, both of whose faces were covered by a gray dot which resembled the dot placed over the face of the plaintiff in the William Kennedy Smith rape trial. The ad revealed that both of the candidates were Clinton. Another Bush ad used computer technology to alter a photograph of Clinton and Gore. In this ad, a photograph of Ted Kennedy is superimposed over Gore's face so that the image created is of Clinton and Kennedy shaking hands. The ad speculates about who might be appointed to important posts under a Clinton presidency.

The increasing technological sophistication of advertisers warrants an increasing sophistication in the media's analyses of advertising techniques. The rather sophomoric approach taken by many journalists is inadequate. By pointing out ethically suspect approaches in ad watches, journalists may indeed help to create a better informed electorate. However, a possible explanation for this lack of coverage is presented by Wolinsky: "... the sheer volume of truth boxes was beyond the capacity of the newspaper's limited newshole. During the final weeks of the campaign, when the most negative and deceptive ads were being aired the Times was forced to pare back its style, publishing ... only when the deception was blatant. ${ }^{\prime 30}$

Although newspapers analyzed for this study were located in areas that held 1992 elections for the offices of Senate, House of Representatives, and President, presidential ads were covered in the majority of ad watches. In fact, $70 \%$ of advertisement features focused on the presidential campaign. In comparison, only $22 \%$ of ad watches covered Senate elections and only $3 \%$ centered on the House of Representatives. Perhaps these findings can be attributed to higher involvement for voters during presidential campaigns. Or possibly, data can be attributed to the fact that three high-profile candidates ran for President in 1992. West (1993) explains, "In general, the number of stories has fluctuated considerably, depending on the closeness of the race ... This was particularly true in 1992, as the three-way battle between Bush, Clinton, and Perot prompted a dramatic increase in news stories." 31

The closeness of the 1992 presidential race may be reflected in the finding that the content of ad watches was fairly evenly distributed among the Republican, Democrat, and Independent parties. A content analysis of television news coverage from 1972 to 1992 indicated that on the whole, Republican ads received the most media coverage (44\%). ${ }^{32}$ Likewise, data from the current study showed that Republican advertisements received slightly more coverage ( $34 \%$ ) than ads for other political parties. This finding is of particular interest in regard to Kaid's finding that only $50 \%$ of Bush's ads were negative, compared to an overwhelming $69 \%$ of Clinton's ads (the majority of Perot's ads were nonopponent focused). ${ }^{33}$ Yet, Democratic ads received only $30 \%$ and Independent ads received only $25 \%$ of the article coverage. The unusually high percentage of coverage for Independent advertisements may be due mostly to the charisma of Ross Perot and his unique advertising strategies, such as his thirty-minute infomercials. Such findings indicate that media professionals should be aware of potential biases in framing ad watches. In the interest of fairness, journalists should be more cautionary in their coverage of political advertisements.

Although the findings from this study support previous research, several limitations must be discussed. First, researchers cannot be sure that all ad watches were collected. For the majority of the papers, researchers relied upon newspaper indices. However, for the Miami Herald, no such source could be located. Therefore, researchers scanned all newspapers 
appearing within the search parameter. Secondly, articles were reproduced from microfilm. This may have distorted the original size of the articles and, thus, may have skewed measurements of coverage.

Despite limitations, the findings of this study are of value. They enhance previous findings and provide grounds for future research inquiries. For example, scholars could investigate the link between agenda-setting and political ad watches. In addition, as candidates place greater importance on news coverage, research could be conducted on the strategies and tactics that candidates employ in ads to gain media attention. As the visual content of political advertisements becomes an increasingly important component of ad watches, scholars could investigate the "videostyle" communicated and the "ethically suspect categories" identified in ad watches. Moreover, future analyses would be merited in nonpresidential years. Such studies could investigate the amount of media attention given to other levels of races when no presidential race is attracting the majority of media attention. Greater research also needs to be conducted on the blurring effect between political advertisements and political news coverage. Finally, a study comparing televised ad watches to newspaper ad watches would be beneficial to communication scholars, political consultants, and journalists.

\section{NOTES}

1. Darrell M. West, Air Wars: Television Advertising In Election Campaigns, 1952-1992 (Washington, DC: Congressional Quarterly Inc., 1993), 111.

2. See Thomas E. Patterson and Robert D. McClure, The Unseeing Eye: The Myth Of Television Power In National Politics (NY: Putnam, 1976); Thomas Patterson, The Mass Media Election (NY: Praeger, 1980).

3. West, Air Wars.

4. Roger Ailes, "TV-Spot Critics: 'Boring And Biased,'” Washington Journalism Review 13 (January/February 1991): 27.

5. Kathleen Hall Jamieson, Dirty Politics: Deception, Distraction, And Democracy, (NY, London: Oxford University Press, 1992); Daniel S. Hinerfeld, "How Political Ads Subtract; It's Not The Negative Ads That Are Perverting Democracy, It's The Deceptive Ones," The Washington Monthly, May 1990, 12-22.

6. Linda Lee Kaid, Robert H. Gobetz, Jane Garner, Chris M. Leland, and David K. Scott, "Television News And Presidential Campaigns: The Legitimization Of Televised Political Advertising," Social Science Quarterly 74 (summer 1993): 274-85.

7. Michael Pfau and Allen Louden, "Effectiveness Of Adwatch Formats In Deflecting Political Attack Ads," Communication Research 21 (June 1994): 325-41.

8. David R. Runkel, ed., Campaign For President: The Managers Look At '88 (Dover, MA: Auburn House, 1989).

9. Jamieson, Dirty Politics, 123.

10. West, Air Wars.

11. Jamieson, Dirty Politics.

12. Kaid et al., "Television News."

13. Jamieson, Dirty Politics.

14. Leo C. Wolinsky, John Sparks, John Funk, Emily Rooney, Greg Lyon, and Lynn Sweet, "Refereeing The TV Campaign," Washington Journalism Review 13 (January/February 1991): 22-29. 
15. Darrell M. West, Montague Kern, and Dean Alger, "Political Advertising And Ad Watches In The 1992 Presidential Nominating Campaign" (paper presented at the annual meeting of the American Political Science Association, Chicago, IL, 1992).

16. Montague Kern, Darrell West, and Dean Alger, "Political Advertising, Ad Watches, And Televised News In The 1992 Presidential Election" (paper presented at the annual meeting of the American Political Science Association, Washington, DC, 1993).

17. Joseph N. Cappella and Kathleen Hall Jamieson, "Broadcast Adwatch Effects: A Field Experiment," Communication Research 21 (June 1994): 342-65.

18. Kern, West, and Alger, "Political Advertising, Ad Watches, And Televised News."

19. Lynda Lee Kaid, "Ethics In Televised Political Advertising: Guidelines For Evaluating Technological Distortions" (paper presented to the International Communication Association, Washington, DC, 1993); Lynda Lee Kaid, "Ethical Dimensions Of Political Advertising," in Ethical Dimensions Of Political Communication, ed. R. E. Denton (NY: Praeger, 1991).

20. Coders analyzed a sample of 10 articles on political advertising to determine intercoder reliability. Reliability ranged from +.78 to +1.00 , with an average intercoder reliability of +.91 . The category reflecting type of expert used in the ad watch achieved the lowest level $(+.78)$ of agreement. Coders achieved perfect agreeability $(+1.00)$ on categories such as: placement of story, picture of advertisement shown, number of ads shown, advertisement copy given, candidate name identified, candidate gender, and office sought. For the formula used, see Robert C. North, Ole Holsti, M. George Zaninovich, and Dinl A.Zinnes, Content Analysis: A Handbook With Applicants For The Study Of International Crisis (Evanston, IL: Northwestern University Press, 1963).

21. Kaid et al., "Television News."

22. Kaid et al., "Television News."

23. West, Air Wars; Kaid et al., "Television News."

24. L. Patrick Devlin, "Contrasts in Presidential Campaign Commercials of 1992," American Behavioral Scientist 37 (November 1993): 272-89; Lynda Lee Kaid, "Political Advertising In The 1992 Campaign," in The 1992 Presidential Campaign: A Communication Perspective, ed. Robert E. Denton (Westport, CT: Greenwood, 1994), 111-27.

25. Jamieson, Dirty Politics; Lynda Lee Kaid and Dorothy K. Davidson, "Elements Of Videostyle: Candidate Presentation Through Television Advertising," in New Perspectives On Political Advertising, ed. Lynda Lee Kaid, Dan Nimmo, and Keith R. Sanders (Carbondale, IL: Southern Illinois University Press, 1985), 184-209.

26. Kaid, "Ethics In Televised Political Advertising"; Kaid, "Ethical Dimensions of Political Advertising."

27. Kaid et al., "Television News."

28. Jamieson, Dirty Politics; West, Kern, and Alger, "Political Advertising And Ad Watches In The 1992 Presidential Nominating Campaign"; Kern, West, and Alger, "Political Advertising, Ad Watches, And Televised News."

29. Kaid, "Ethics In Televised Political Advertising."

30. Wolinsky et al., "Refereeing the TV Campaign," 22.

31. West, Air Wars.

32. Kaid et al., "Television News."

33. Kaid, "Political Advertising In The 1992 Campaign." 